\title{
Design the Sleeve of the Adjust Screw and Nut Locking Device
}

\author{
XU Chao, Du Xiang-yang \& JIA Cong \\ Shanghai University of Engineering Science, Shanghai, China
}

\begin{abstract}
Our paper work on the design of the molded case circuit breaker's automatic production line .Screw in the trip (located at the hot end of the bimetallic strip) extended length to the length of the circuit breaker tripping time play a decisive role, so the thermal trip is the core component of the molded case circuit breaker. The adjust screw and nut locking device locks the nut in the trip actions are done by outer sleeve, So for the completion of the design of the sleeve on the device is very important. In this paper, through the experiment found deficiencies in the design of the sleeve and then improve the design. Using this way, innovative designing on the basis of the traditional nut sleeve, to meet in A installation conditions can successfully complete the action of the sleeve screwing nut.
\end{abstract}

KEYWORD: the adjust screw and nut locking device; thermal trip; sleeve

\section{INTRODUCTION}

The adjust screw and nut locking device need to complete for molded case circuit breaker tripping device adjust screw nut locking. Because of its study of circuit breaker performance detection unit in technology and in theory, there is a big difficulty, therefore, at present the research work still has great development space [1].Following the increase demand of global market, the Low-voltage electrical appliances production and processing industry of our country are rapidly development , and gradually from small scale production to mass customization production, the production line changed to intelligent production line is imperative[2].The next five to ten years will enter a new intelligent mechatronics, energy saving, security, environmental protection and other high and new technology of low-voltage circuit breaker production rapid development period so almost all international companies manufacturing low voltage circuit breaker are working on improving the production line efficiency.

As a project in the circuit breaker performance testing, long time delay detection is very important .The long time delay of intelligent detection system which is high speed, high precision, reliable is one of the important conditions to realize the automatic circuit breaker. The key institutions to long time delay of circuit breaker is the thermal magnetic release, which can provide magnetic protection and thermal protection. The thermal protection, in other words, is overload protection. Thermal protection: hot components get hot when an current passes through the release (direct thermal current passes the bimetallic strip directly), bimetallic strip deformation because of the heat, the triggered screw on the metal will contact with the bolt rod when the deformation gets to a certain extent, until the bolt rod drives the release to cut off the power after moving a certain distance. The main work of the long time delay is to test the output current of the release, causing the release heated and bimetallic strip out of shape, lead to the triggered screw getting close to release lever, adjusting the triggered screw length automatically (or artificially) Adjustment trigger screw adjustment precision decided long time delay circuit breaker products performance is good or bad.

\section{INTRODUCTION THE THERMAL TRIP}

The thermal trip is the core component of molded case circuit breaker, it operated overload protection, short circuit protection, etc. It is using the bimetallic strip thermal deformation characteristics, with the deforming force driving the trip mechanism moving, so as to cut off power supply.

The working principle of the overload protection time delay protection agencies: When the circuit breaker in the loop current exceeds a certain rating, 
the trip thermal bimetal's heat accumulation in the slow deformation as shown in figure 1.Thermal bimetallic strip buckling deformation, when the deformation reaches a certain degree. At the end of the trip screw touched trip fragment, in a certain amount of time. When the deformation force reaches a certain value, produces a pressure to dial the fragment, makes the circuit breaker off contact, to cut off the main circuit.

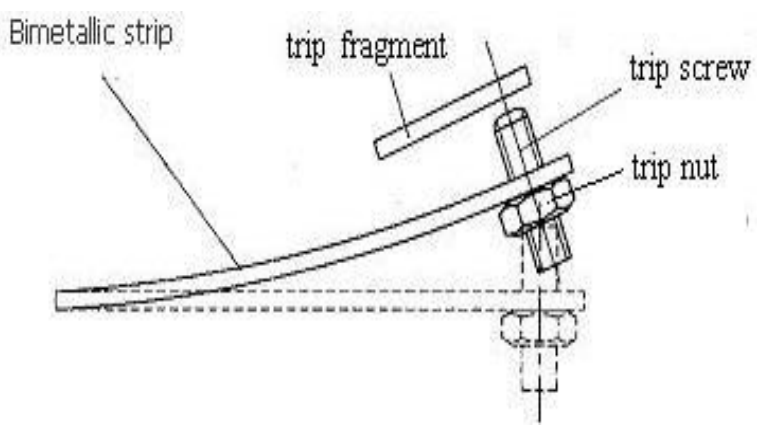

Fig1. The thermal trip[8]

\section{DESIGN THE SHAPE OF THE SLEEVE}

Using the experimental data and the actual operation experience expected movement way. This caused in the process of regulating sleeve of trajectory tracking, gesture and practical operation of trigger screw trajectory, a larger posture deviation. Making the sleeve center axis and screw center axis with a certain Angle. And before the sleeve and nut contact, the sleeve's rotating speed is less than $10 \mathrm{r} / \mathrm{min}$ while the trip nut is static. According to the above conditions to design the size of the outer sleeve shapes in order to rapid alignment of sleeve and nut. And ensure the trip nut can smoothly exit from the sleeve after completed the action of tighten the trip nut.
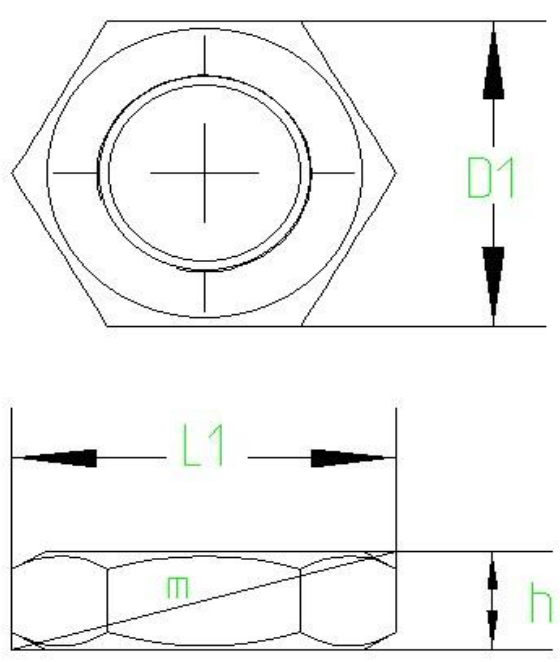

Fig.2 Trip nut

Figure 2 for trip nut $\mathrm{h}=1.8 \mathrm{~mm}, \mathrm{D} 1=6 \mathrm{mmBecause}$ the trip nut is hexagonal according to geometric relationship has the formula:

$$
\begin{aligned}
& \mathrm{L}_{1}=\mathrm{D}_{1} \div \sin 60^{\circ}=6.928 \mathrm{~mm} \\
& \mathrm{~m}=\sqrt{h^{2}+L_{1}^{2}}=7.16 \mathrm{~mm}
\end{aligned}
$$

Due to the center of the sleeve shaft and the center of the screw shaft with a certain Angle. At this time the actual diameter of the trip nut is the hypotenuse long. the hypotenuse is $\mathrm{m} \cdot \mathrm{m}=7.16 \mathrm{~mm}$.

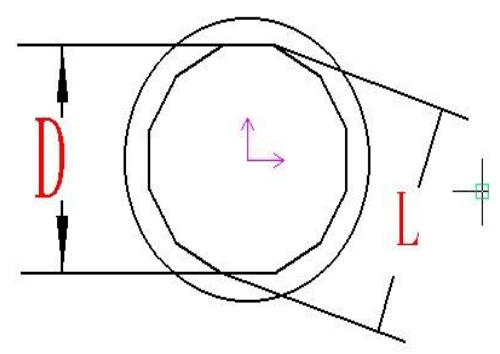

Fig.3 Sleeve top view

According to the shape and size of the hexagonal nut, we design the shape and size of the sleeve. The rotating sleeve and nut will align once per 60 degree when the shape of the internal sleeve is hexagon. According to this, the more number of the edge of the internal sleeve the more easy for the rotating sleeve and nut to align with. However, base on the smaller size of the nut, the size of the sleeve will be small relatively. It will be take much time and more money to machine, if the number of the internal sleeve is to many. So we chose dodecagon as the shape of the internal sleeve After weighing the pros and cons, as shown in Fig.3. In the Fig.3, D is he opposite side distance of the dodecagonal internal sleeve, $\mathrm{L}$ is the diagonal distance. The geometric relationship between $\mathrm{L}$ and $\mathrm{D}$ is.

$$
\frac{\mathrm{D}}{\mathrm{L}}=\sin 75^{\circ}
$$

Based on the experience of the sleeve to screw the nut, we have found that the nut will be screwed by the sleeve if $\mathrm{D}<\mathrm{L}$. According to the restrictive conditions of he manufactured sleeve we have found that the laser positioning system cannot be installed on the workbench because of the work space limitations in practice. This will lead to at an angle between hexagonal nut center shaft and sleeve shaft when the screwed sleeve exit. And will cause the viscous phenomenon between screwdriver and nut. The phenomenon will lead deformation of the bimetallic strip and casus the circuit breaker assembly precision error increase as well. We have found that the viscous phenomenon caused by the dimension of the sleeve $\mathrm{L}$ is smaller than the nut $\mathrm{m}$ in the experiments. So we added the limit conditions based on this: 
$\frac{\mathrm{D}}{\mathrm{L}}=\sin 75^{\circ}$

$m=\sqrt{h^{2}+L_{1}^{2}}$

$\frac{D_{1}}{L_{1}}=\sin 60^{\circ}$

$L>m$

$D<L_{1}$

$\mathrm{D}_{1}=6 \mathrm{~mm} \quad h=1.8 \mathrm{~mm}$

The dimension of dodecagon of the internal sleeve is as following: $6.916 \mathrm{~mm}<\mathrm{D}<6.928 \mathrm{~mm}$ after calculation. The edge of the dodecagon $\mathrm{D}$ precision would be manufactured size to $0.01 \mathrm{~mm}$. Take he manufacturing cost into consideration, we cannot reach the precision.



Fig.4 Sleeve top view

How to solve the problem is the innovation in this paper work. The key point is the geometric relationships between $\mathrm{D}$ and $\mathrm{L}$ in our research. However, we cannot change the $\mathrm{D}$ and $\mathrm{L}$ in the dodecagon. So we put forward third geometrical quantity d, we used arc in Fig.4 to replaced the original line of the internal dodecagon of the sleeve. The new added geometrical quantity diameter of the circle formed by twelve arc couple, as it shown in the Fig.4. We can solve the former problem through the new added geometrical quantity d to replace the $\mathrm{D}$ in the limit condition. We can get the new limit condition $\mathrm{d}<\mathrm{L} 1$. Redesign this, the edge of the internal dodecagon is $\mathrm{D}=7.5 \mathrm{~mm}, \mathrm{~L}=7.16 \mathrm{~mm}$, because the $\mathrm{m}=7.16$ meet the limit condition $\mathrm{L}>\mathrm{m}$. The designed $d=6.5 \mathrm{~mm}$, because the $\mathrm{L} 1=6.92$ meet the limit condition $\mathrm{d}<\mathrm{L} 1$. We can actually manufacture the sleeve.

However, the sleeve is constantly moving forward along the nut central axis, The advancing speed of the sleeve is $\mathrm{V}$, and the sleeve rotating speed is $n=10 \mathrm{r} / \mathrm{min}$. The M3 screw standard pitch is $0.5 \mathrm{~mm}$, it means the nut increase $0.5 \mathrm{~mm}$ each turn. Because the nut driven by sleeve, the nut's rotating speed is also $10 \mathrm{r} / \mathrm{min}$. we can calculate the nut rising speed is $5 \mathrm{~mm} / \mathrm{min}$. In order to set the nut into the sleeve, requires $\mathrm{V}>\mathrm{V} 1$. However the trip nuts at different initial positions in molded case circuit breaker. It make some nuts in the depth of the sleeve is too deep.

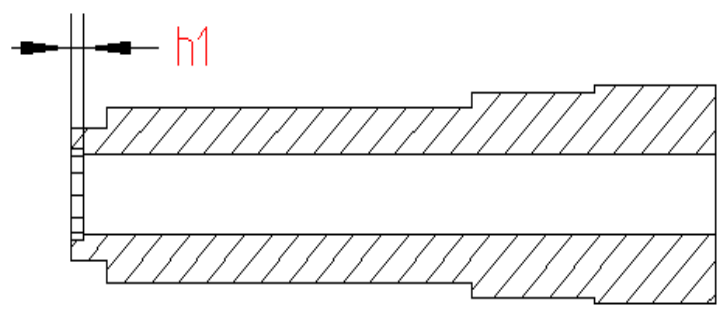

Fig.5 Sleeve sections

While some nuts into the sleeve is very shallow that the nut can not be tightened. In order to guarantee the quality of the product. according to the most shallow sleeve nut into position to design V1 speed value. This caused some nuts deep too deep into the sleeve. The sleeve will be interference the screw fixation basal plane, the basal plane si the bimetallic strip. In order to guarantee the nut can enter enough depth for the sleeve fully tighten the nut, but not too deep into the sleeve that will be interference the screw fixation basal plane. To meet the above requirements, design a step into the sleeve to limit the depth of the the nut in the sleeve. the depth of the step is h1.As shown in figure 5. Found after repeated experiments. When $\mathrm{h}_{1}=\frac{2}{3} h$, the nut will be fully tighten .

\section{CONCLUSIONS}

Through the external sleeve design research step by step to solve the problem. Successfully designed the sleeve that meet the molded case circuit breaker device locking the nut function. In the process of sleeve tightening nut, the upper of the nut is always higher than sleeve。In this way the sleeve will not interfere with the base surface of screw. Reducing the time of tighten the nut and after tightening the nut. It can successfully retreat from the sleeve. Improving the adjust speed and accuracy.

\section{REFERENCES}

[1] Huan En-nian. Low-voltage electrical appliances in China import and export situation in 2006. High and low voltage electrical appliances in China, 2007 (2): 20-21

[2] Chen Degui. Recent low voltage apparatus technology developments. Electric era, 2007 (1): 70-75 